\title{
The Socio-Economic Trajectories of Migrant Street Vendors in Urban South Africa
}

\author{
Dr. Robertson K. Tengeh \\ Faculty of Informatics and Design, \\ Cape Peninsula University of Technology, South Africa. \\ E-mail: rtengeh@yahoo.com
}

\section{Cyprian Y. Lapah}

Doi:10.5901/mjss.2013.v4n2p109

Cape Town, South Africa

\begin{abstract}
:
This study investigated the means used by immigrants for their insertion into the economic landscape of the entrepreneurial cities of their host countries using street vendors in Cape Town as a case study. The concept of social network was central in the explanation of the mechanism of immigrant insertion in the entrepreneurial city. It helped to explain some of the strategies used by immigrants for their insertion into the market space of urban areas in the destination country. The study was based on a survey of two hundred and eight (208) immigrant vendors from other African countries in five suburbs of Cape Town. The study adapted a mix research approach in which a survey questionnaire, focus group discussions, personal interviews, and observation were utilised to collect and analyse the data. The results of the analysis showed that nationality underpinned by social networks was a major factor in the socio-economic trajectories of immigrants in urban South Africa.
\end{abstract}

Key words: market niche, economic insertion, entrepreneurial city, social networks and African immigrants

\section{Introduction}

Migration has been on the increase with the improvement in technology and globalization (De Haas, 2009; Schapendonk, 2012). In the same light, migration into South African cities took an upward turn especially after the fall of Apartheid Regime, (Peberdy \& Rogerson, 2000). The collapse of the Apartheid Regime in the early nineties meant the renovation of cooperation between South Africa and its neighbours as well as the rest of the African continent and the world at large. This gave rise to what Peberdy and Rogerson refer to as "the New Immigration Regime" which refers to the new trend of immigrants coming into the country mostly from the SADC region and the rest of Africa as opposed to earlier immigrations which were mostly from Europe and Asia (Peberdy \& Rogerson, 2000). Despite the country's restrictive policy on African immigrants, their numbers have been on the increase. The fall of Apartheid in South Africa also led to the reinsertion of South Africa in the informal trade networks (Crush \& McDonald, 2000). Many of the African immigrants have therefore seized the opportunity to become small entrepreneurs due to a number of factors. These factors include the Country's immigration policy which is aimed at making the stay of these particular immigrants temporary and may not easily get jobs, the shrinking of major employing sectors such as mining and agricultural sectors (Standing et al. 1996 cited in Crush \& McDonald, 2000) and consequently the scarcity of jobs.

Immigrants coming from lesser-developed countries compared to South Africa especially from Africa are therefore often faced with the problem of where to stay, what to do for a living once they get to their final destinations. In most cases they have to start with the informal sector probably as small-scale entrepreneurs (Tengeh, Ballard \& Slabbert, 2011). Many immigrants in South Africa resort to street vending as a starting point for their economic insertion. Many of them especially from other African countries find it as a suitable means of survival. Coming from different socio-economic, cultural and political backgrounds, these immigrants resort to different ways of migrating and different ways of adapting as concerns their livelihood in their new places. 


\subsection{Problem Statement}

Though much has been written on migration and entrepreneurship which is the area of this research, little has been done on the relationship between migration and the dynamics of economic insertion of the migrants especially those using street vending as a "breakthrough" for their economic insertion. Many studies on street vendors in South Africa have also not elaborated on the migrant street vendors and the link between their migration process and their insertion in the South African cities where as most studies in the field of migration and entrepreneurship focus on remittances by the migrants as well as their impact on both their place of departure and on the place of destination. We therefore argue that immigrant street vendors in South Africa rely more on their relations and self-employment for their socio-economic insertion and survival and therefore concur with Light's (Light, 2004) assertion that immigrants do not "take away" jobs from natives but instead contribute in the supply of jobs in the destination country. The social networks used by these immigrants during their migration process also help them in their socio-economic insertion in South African cities.

\subsection{Aims of the Study}

The aim of this study is to establish the linkage between migration, social and the economic insertion of migrants in the entrepreneurial city using street vendors in urban South Africa as a case study. It explores the role of social capital or networks on the migration and economic integration of migrants using immigrants involved in street vending as a case study. It therefore seeks to explore ways in which immigrants negotiate for their insertion in the 'entrepreneurial cities' of their destination country. The study will seek to establish this linkage by trying to answer the following questions:

\subsection{Research Questions}

The study therefore seeks to answer the following questions:

1. To what extent do the various migratory trajectories influence the choice of market niche used by African immigrants for their insertion in their host country?

2. What type of connections do vendors create and do these relationships/connections help in the acquisition of space, capital and experience needed for their business?

3. What role does residential mobility play in the choice of activity of these immigrants?

4. How has street vending helped in changing the livelihoods of these immigrants?

\section{Literature review}

\subsection{Theoretical Framework}

The Socio-economic trajectories in this paper refer to the social and economic adaptations by immigrants in their host cities in order to sustain their lives and gain stability in their host cities. From the literature review done, there are many theories that have been elaborated in relation to international migration as well as 'immigrant entrepreneurship' (specific area of the study). Early researchers in this field grouped the migration theories into economic, demographic and sociological theories.

The Economic theoriesare generally formulated along the following along the following lines:

- Neoclassical macroeconomic theories which held the view that migration is caused bydifferentials in the demand and supply of labour between nations. Hence places of high labour shortages would attract migrant labour from a place of abundance.

- The Neoclassical microeconomic theory on its part holds that the decision to migrate is rather determined on the micro scale by the individuals who decide to migrate to other countries judging from what they hope to gain from the migration process.

- The "New economics theory" or "New economics of labour migration theory of migration" on its part holds that migration occurs because families or other social groups, in a bid to diversify their income earnings as well as risks, decide on some of their members to migrate.

- The Dual market theory of migration believes that migration occurs because of wage differences between countries. Hence low-wage migrants are attracted by relatively high-wage employment in other countries (Myron \& Teitelbaum, 2001). Other theories as given in (Myron \& Teitelbaum, 2001) include the "demographic 
differential theory" that is based on differences in population numbers and the "institutional theory" or what has been termed "world systems" by other scholars which dwell on the role of intermediaries such as multinational firms in migration. This theory also holds that migration has become a form of business.

The most explicit and most important theory of migration is the Network Theory developed by Massey (Light et al. 1989). According to this theory, Massey, Arango, Hugu, Kouaouc, Pellegrino and Taylor, (1993) hold that migrations lead to the formation of networks which in turn feed subsequent migrations. This means that once migrations are initiated, networks are automatically formed and further migrations take place independently of the initial push and pull factors that cause the migration. Massey advances two reasons how these networks support and promote further migration.

- Firstly, once migration has reached a certain threshold, they result in autonomous social structures which ease migration in the form of reduced social, economic and emotional costs involved in the process of migration. Hence networks act like some sort of "shock absorbers" in the migration process.

- Secondly, networks also support migration in the sense that they act as risk diversification for family members of those who migrate. This tie in the views of the New Economic Theory earlier discussed.

The precursors of the Network theory also hold that migration gets to a stop at one point where there is what they term "economic saturation" where the job market in the mainstream economy of the receiving country is full. This then leads to what he calls "Flow-backs". This is because migrants find it more and more difficult to find jobs and accommodation. This is the point where other scholars like Light Ivan and others disagree (Light et al. 1987, 1989, 2004). On their part they hold that migrants do not only rely on their destination countries to get jobs but also create jobs for themselves through these same networks as he put it "networks either improve the efficiency of searches or increase the actual supply of opportunities or both". We hold this view in relation to the street vendors in urban South Africa. This happens through immigrant entrepreneurship. Migrants, through their personal initiative and cooperative efforts apply capital to the employment of themselves and of co- ethnic immigrants in their destination countries. This therefore counteracts the effects of economic saturation as postulated by Massey and others (1993). However, Massey and others have done much in fusing all theories discussed earlier theories (discussed at the beginning) into one explicit theory and the first that could be used to answer the question as to why migration persist even after the initial causing factors are no more valid.

Another theory worthy of mention that links migration to employment and entrepreneurship is the Restructuring theory or the Demand-driven theory of migration elaborated by Saskia Sassen (Light, 2004). This theory holds that the main reason for the growth of immigration and the development of the informal sector is the imbalance between the economies of the sending country and the receiving one (mostly the richer country). According to this theory the growth in the economies of the developed countries leads to a demand of low-wage workers to serve as housekeepers, gardeners and other low-paid jobs which the nationals are reluctant to do. Immigrants therefore readily migrate to take up these jobs. This is a further explanation of the 'Polarization theory' developed earlier by Moore and Pinderhuge (Light, 2004). This theory was further used to explain the increase in the informal sector of the economies of the receiving countries. It however also incorporates most of the ideals of the Economic theories discussed above and focuses more on the expansion of the informal sector (by nationals and not by immigrant initiatives) as a result of immigration. This may not be the case with African immigrant street vendors in South Africa. No doubt the theory has been criticized once more by Light in the above-quoted paper and even modified by the author (Saskia) who, both hold the view that part of the growth in the informal sector can be attributed to the "importation of survival strategies" by the immigrants from their places of origin to their destination countries. Hence, they concluded that immigration is not only "demand-driven" but is also "supply-driven". This brings the idea of immigrant entrepreneurship and falls in line with the economic activity of the immigrant street vendors in urban South Africa.

Another related theory is that of the Entrepreneurial City. The theory perceives the city as a product that has to be marketed. According to the precursors of this concept, many cities especially in the developed world are being managed from a market point of view. This is because most cities are increasingly being regarded as commodities that have to be properly managed to get the best profits. Hence, the idea has given rise to what has been termed "Entrepreneurial Urban Governance" (EUG) which refers to strategies that are aimed at making the city more competitive (Crossa, 2009). One characteristic of the strategies is that of transforming cities from places of work to attractive place for local and international investment (Ghannam 1997 cited in Crossa, 2009). These strategies are also characterized by the privatization of public urban space and the emergence of gated communities (such as malls).There is therefore high competition for urban space as priority is given to the construction of malls, convention centers, sports centers and cultural spaces such as museums. In the face of this competition, the poor sectors of the city are often faced with the 
problem of acquiring space for their survivalist activities. Immigrant street vendors are certainly faced with the problem of "fitting" themselves in the entrepreneurial city.

It is important to note that the role of social capital/networks in the migration of the migrants and their economic insertion in the entrepreneurial city will be the focus of the study.

\subsection{Migration, social networks and entrepreneurship}

It can be seen from the theoretical framework that social capital (through social networks) plays an important role in the migration process and as well as the incorporation of the migrants both in the political and economic frameworks of their host countries. In the study of the impact of the social networks on the immigrant womens' incorporation Elizabeth Gidengil and Dietlind Stolle underscore the influence of social networks (Gidengil and Stolle 2005). Among the factors that facilitate political incorporation, the authors cite the prior experience of immigrants in politics, the length of stay in the host country, and the country of origin. By allusion, these factors may also apply in the insertion and incorporation of immigrants in the economic framework of the receiving country.

Fennema and Tillie (cited in Gidengil \& Stolle, 2005) showed that there exists a strong correlation between the incorporation of immigrants and the "density" of what they call "associational networks". The strength of one's network depends on the type of people the person associates with (Gidengil \& Stolle 2005; Tim, 2008). Also, the more relationships one creates, the wider his social network. Hence it may be concluded that the insertion and incorporation of immigrants depend on the strength (density) and quality of their networks.

Social capital facilitates migration through migration networks as well as the economic incorporation of the immigrant (Light, 1989). As the migration networks increase, they facilitate the incorporation of its members either by broadening the searches for jobs or by increasing the supply of jobs through what has been generally termed "ethnic economies" (Light et al., 1989). "Ethnic economies" can be defined as business ventures established, owned and managed mainly by immigrants. Through ethnic economies, immigrants apply self-generated capital to improve their livelihoods as well as that of their fellow countrymen and other immigrants who are employed in these enterprises. Tim Elrick defines a migration network as the "aggregate of all migrants' networks" in relation to certain groups (same nationality, region or ethnic group) whereas the Migrant network on its part is defined as the "migrants' social connections with migration-related knowledge" (Tim, 2008). This can be made up of family members, friends or even acquaintances. $\mathrm{He}(\mathrm{Tim})$ points out the fact that migration networks of groups are built on mutual cohesion of the members who use the social capital accumulated within the network. Migration networks therefore play a vital role in the economic insertion and the incorporation of migrants in their host country.

\subsubsection{Migration networks and socio-economic integration}

Once migrants reach their destination country, they are confronted with the problem of sustaining their livelihoods. One of the ways of insertion is by becoming entrepreneurs ( Tengeh et al,. 2011). As Pécoud affirms, "entrepreneurship is an important means of incorporation of immigrants in their host countries" (Pécoud, 2005). The migration or social networks facilitate immigrants to become entrepreneurs in their host country. Light and others identified three ways by which social networks help fellow migrants in investing in their host countries (Light et al., 1989).

- Networks facilitate the supply of low-cost labour to immigrant entrepreneurs who have established ethnic enterprises. This happens as immigrants tend to employ mostly fellow immigrants in their enterprises probably due to the faith they have on them as people with a common objective but also as they would often demand lower rates compared to locals.

- Networks provide the necessary information to entrepreneurs as well as would-be immigrant entrepreneurs. This information covers issues like how and where to start a business, the pricing policies of the country, the best sectors to invest, dealing with public bureaucracies and possible obstacles in the various possible ventures. This information is often concealed to people who do not form part of the social or migration network.

- Through migration networks, immigrant entrepreneurs can get access to various forms of aid. Hence initial training and capital can easily be gotten through these networks. Immigrants easily get an apprenticeship and start-up capital through associations and family members (who constitute this network).

One may now ask the question "why do immigrants engage in informal enterprising?" Many reasons have been advanced by different authors to explain immigrants' involvement in business activities (both formal and informal) in their host countries. Among some of the reasons, one can generally identify: 
- The high unemployment levels among the immigrants compared to natives exacerbated by discriminatory employment policies governing employment in most receiving countries (Zuberi \& Sibanda,. 2005, Tengeh et al., 2011). And the lack of legal documents that can permit their employment in the formal sector of their host country (Tara, 2008).

- Immigrant entrepreneurs easily find some sectors abandoned by the natives such as petit trade (hawking) (Waldinger 1994 cited in Pécoud, 2005).

- Due to the increasing need for immigrants to acquire certain goods and services specific to the immigrant population, immigrant entrepreneurs emerge to supply these goods and services that are in high demand and common within the immigrant community. These include especially foodstuff and certain services like conveyance of remittances.

- Immigrants are motivated by the zeal to create their own enterprises in their home countries once they go back home and can easily accumulate the capital and experience in the host countries where the conditions are favourable to get it started.

The poor easily finds livelihood in the informal sector. Hence poor immigrants easily find the informal sector as a breakthrough in their search for a "new life". This of course is facilitated by the social networks of which they form part. Factors that contribute to immigrants' insertion in the informal sector of their host countries include:

- The low capital needed to start the business. In most cases, migrants are always provided with the much needed capital by some relations (Tengeh et al., 2011).

- The legal framework surrounding the operation of this form of business. Most often, there is little or no bureaucratic work needed to go through in order to start up business in the informal sector. This therefore encourages most immigrants whose status in the host country is not stable or even not legal.

- The development of partnerships between the formal and informal sector also favours the insertion of immigrants in the informal sector. A case in point is the development of partnerships by textile companies in Britain with immigrant street traders (Pécoud, 2005). This is similar to what some authors term "fronts".

While some immigrants enter into business in their host countries as big entrepreneurs, it is true that a majority of immigrants from developing countries are often involved in informal trade especially street vending owing to the fact that they come from poor backgrounds or might have gone through major setbacks in their lives in their home countries.

\subsection{Street vendors as part of the informal sector}

Street vending is fast becoming a global phenomenon. Though it is mostly practiced in developing countries, it is not uncommon in the developed world. Millions of people earn their livelihood by selling on the streets.

In developing countries especially in Africa and Asia, street vending represent between 73 and $95 \%$ of employment in trade and contribute about 50 to $90 \%$ to the GDP in some countries. A study done by Muiruri (2010) in Nairobi-Kenya showed that $97 \%$ of the female population depended solely on street vending for their livelihood.

In South Africa, the 2000 Labour Force Survey estimated that there were 445000 street vendors in the country while street vending accounted for $26 \%$ of value added in trade in 1999 (ILO, 2002). How do these vendors acquire space, capital and experience? What are their socio-economic characteristics? What are their problems and some attempted solutions? These are some of the issues we will be looking at in the rest of this part of the review. A street vendor can be defined as a person who offers goods or services for sale to the public without having a permanent built-up structure and not being captured by the tax system of the geographical area in which he or she trades. Street vendors may have semi-permanent trading structures or mobile. They range from people who sale manufactured goods through providers of services like hairdressing and shoe repairs to those acting as agents of shops and well-established firms (in the formal sector).

Street vendors seem to have some generally common socio-economic and demographic characteristics though there are also great differences on an individual scale.

\subsection{Characteristics of street vendors.}

\subsubsection{Socio-economic}

Street vending is often associated to people with no skills and low levels of education who cannot pick-up jobs in the formal sector due to this handicap (Pécoud 2005; Nontyatyambo, 2009; Kamala et al. 2007). They probably get their 
training from the street through constant practice of the trade and their capital mostly from personal savings. (Kamala et al. 2007). Studies done in both Johannesburg CBD and Durban Metropolitan in 1997 (Lund 1998) showed that the level of education of street vendors was generally very low with $10 \%$ and $18.3 \%$ of vendors not having primary education in both Johannesburg and Durban studies respectively. Another half of the vendors in both cities had finished only the primary school education (six years of schooling). There are also gender disparities in the level of education with more women than men not having any educational training. This trend also holds true for higher levels of education which are themselves very few among street vendors. However, the author points out that in the Johannesburg study, migrant street vendors had higher levels of education that their South African counterparts (Lund 1998).

On the types of products marketed, street vendors sell products ranging from manufactured goods like clothing and shoes through self-made products like craftworks to services like hairdressing and the sale of insurance and other related services. Lund points out that in South Africa, manufacturing constituted a very small proportion of goods and services sold as opposed to manufactured goods like clothing and cosmetics as well as foodstuff (especially fresh produce) (Lund 1998). This means that many more hawkers sold goods not produced by themselves. Only $3 \%$ of the street vendors sold goods produced by themselves. This is contrary to another study done in Kenya where about half of the street vendors were involved in manufacturing (Claudia Manning 1994 cited in Lund 1998). The studies done in Johannesburg and Durban showed that food accounted for $41 \%$ of the products sold by street vendors, clothing was $37 \%$ and fruits and vegetable carried $30 \%$ while services were the least.

Street vendors are often associated with very low earnings from their activity (Sankaran et al. 2007). Despite the fact that the vendors mostly work under very difficult conditions like selling in the open air exposed to rain and hot sun, with little social protection, they also come back daily with very little as their earnings. This has also been true in the case of Lesotho where the study of Pius Tanga showed that despite more and more poor people in Lesotho being engaged in hawking in a bid to counter the effects of unemployment and poverty, lesser number of these people and actually getting out of the poverty net (Tanga, 1994). In the Durban and Johannesburg studies (cited earlier), the results showed that $54 \%$ of street vendors in the Johannesburg earned an average of 600 Rands per month while $16 \%$ of women earned 200 Rands per month from their trade (Lund 1998). In another study in India, Kamala Sankaran found that vendors earned between 40 and 80 Rupees per day (Sankaran et al. 2007).

\subsubsection{Problems faced by street Vendors}

Street vending has often been characterized by what some authorities would call the "invasion" of street, walks, major junctions, parks and other public areas by poor hawkers who want to make a living by exposing their wares to potential buyers (Vicki, 2005). This means that the acquisition of space for the activity is uncontrolled in most cases. However, there have increasingly been regulatory measures taken to this effect in many urban centers and metropolis especially in South Africa (Tara, 2008). This has also been one of the major sources of contention between street vendors and the authorities (Jenny, 2009; Crossa 2009).

Street vendors often face many problems. Firstly, the very nature of their activity is seen in most cities as a hindrance to the development of the city (ILO, 2002; Nontyatyambo, 2009; Vicki, 2005). This has in most cases led to most of their activities being classified as "illegal" and hence the ensuing problems encountered. Nontyatyambo (2009) asserts that street vending is the most vulnerable career after prostitution in terms of harassments and associated risks involved. The very fact that the activity is often poorly regulated in most cases puts the vendors at the mercy of some government officials like the police who often carry out arrests, confiscation of goods and even demand for bribes. Hence, a constant infringement on the rights of the traders as this may also be accompanied by beatings and even detentions (Muiruri 2010; Nontyatyambo 2009). Jenny Anderson (2009) examines the struggles of informal traders for public space in Zanzibar highlights this contention. Other difficulties common to street vendors are the environmental risks involved in the activity. Here, one may cite the constant exposure harsh weather conditions like heavy rains and harsh sun especially in tropical Africa as the traders mostly carry out their activity in the open areas without any form of shelter (Lund 1998).

\subsubsection{Street trade and past experience}

According to Lund, the relationship between past work experiences and the insertion in the informal sector is generally a neutral one as the above-mentioned studies reveal that about $80 \%$ engage in informal trade not by choice but due to the lack of skills and employment (Lund 1998). However, the study of Pentz in 1992 (cited in Lund, 1998) of Warwick Avenue 
showed that about $75 \%$ of male street traders had had employment in the formal sector. Gender disparities in past experiences have been shown in the work of Nair (1996) of street vendors in Beachfront-Durban (cited in Lund, 1998).

\subsection{Policy on street vending in South Africa}

Policies governing street trade in South Africa have evolved with time. It can be divided into two scenarios namely the situation during the Apartheid era and the post-apartheid era. The legacy of apartheid has had a huge impact on the development of the informal sector in general and street vending in particular. Policies during the apartheid era were aimed at restricting movement and activities (including business activities) of the black (poor) community. This was done through a series of acts. One of those acts was the Native (Urban Areas) act of 1923 which restricted blacks from residing in urban areas (let alone operating any business venture). They (blacks) could only do so if they were recruited to work for the "white men" residing in these areas. This was later modified by 'move-on laws' which stipulated that any street vendor had to be strictly mobile (changing his locations at given time intervals). Other acts which had the same consequences of stifling self-employment include the 'Group areas act' and the 'Development and Trust and Land Act' (Lund 1998).

After much resistance from the national and international communities with the official abolition of apartheid, these acts were discarded and replaced by the 'Business act' in 1991 which removed all the barriers to business in general and informal trade in particular. This was followed by the 'Small Business act' in 1995 that actually aimed at promoting and encouraging the development of the informal sector through the provision of financial services to small enterprises and incorporating the sector in urban planning policies through a participative approach. Policies regarding street vending in urban South Africa have henceforth been enacted by provincial legislatures and municipalities in line with national policies on urban development. One of the cases is the Johannesburg 2030 Development Plan whose implementation started in 2005. In its quest for a "world-class city" the city of Johannesburg embarked on a series of measures in 2005 aimed at "cleaning" the city streets of informal traders and making the city more attractive for investment. The plan was intended to boost investments in the city by ensuring that hawkers were kept off the streets in some areas which affected about 15000 informal traders in 2005. The city officials assert that street traders are "a brake" on growth as new investments are hindered by their activities despite also asserting that the council of Johannesburg is not opposed to informal trading but to "illegal trading. However, one city official could admit the consequences by saying "an African city cannot be like New York (Vicki, 2005).

In view of all the negative impacts of urban policy implementation on the weaker population of the urban frame, many authors and groups have been quick to point out the need for street vending to be incorporated into the mainstream economy and to call for the respect for the rights for the livelihood of the poor members of the society (Nontyatyambo, 2005). Hence any attempt of meeting the millennium development goal on poverty should be through strengthening the informal sector and street vending in particular which is the source of livelihood for a majority of the poor.

\subsection{Role of Associations:}

In view of the conflict between urban planning policies and the very survival of the informal sector in general and street trade in particular, there has been a growing need for the formation of agencies and associations to deal with these problems and empower the 'poor' members of the community to participate in the development of their communities. The most prominent among these associations is the 'Street Net' which is an international alliance of street vendors started in 1995 with members from eleven countries. They then drafted and adopted what has come to be known as the "Bellagio international Declaration of street vendors".Associations would certainly play an important role as far as the success of street vendors and their survival through the activity is concerned. Associations would assist in such matters like assisting in bulk buying; negotiating with local governments for improved amenities, organizing for self-regulation for better marketing and above all fight for the rights of the traders. However in most cases, these associations are either absent or very few or even merely "toothless bulldogs" (Tanga 1994; Lund, 1998).

\subsection{Conceptual Framework}

Having looked at some of the theories and previous studies around migration and street vending, we found that little has been done to explain the link between migration and the negotiation for space in the cities of their host countries by immigrants. 
The migration network theory explains how networks can help in subsequent migration but does not explain the dynamics of these networks in the entrepreneurial city. One may therefore seek to know whether social networks are destroyed after the migration process or continue in the urban area. The restructuring theory on its part holds that the main reason for the growth of immigration and the development of the informal sector is the imbalance between the economies of the sending country and the receiving one but fails to explain how immigrants "fit" themselves into the informal sector in cities. The Entrepreneurial city theory also does not provide an explanation for migrants' insertion in the entrepreneurial city. I therefore argue that the migratory trajectory among street vendors and their economic insertion in the informal sector is a reflection of the extent to which migrants are capable of mobilizing resources from different layers with their web of relations. This translates into different individual strategies to gain access to resources such as housing, capital as well as information and experience in business practices. In the process of establishing themselves as street vendors, it is assumed that different forms of experiences to negotiate for business space may emerge. There could be variations in the socio-economic transformations depending on aspects such as nationality, gender, age, duration of stay, level of education, to name but a few. This study is aimed at establishing the nature of these differences.

\section{Research Methodology}

\subsection{Research Design}

The research design is the guiding framework on how the researcher will get and analyse information. "It situates the researcher in the empirical world" (Keith, 1998). Hence, this research takes a quantitative dimension though there may be some aspects of a qualitative study. This is simply because there is hardly any social science research work that is strictly quantitative or qualitative (Bell, 2005). Since the research is based on the immigrant vendors and it is very difficult to study all of these vendors and whose sampling frame is not available, it is evident that the design is a cross-sectional one or "correlation survey" designs (Keith, 1998). In the absence of a sampling frame, the "purposive" was utilised. The sampling units (respondents/participants) were subjectively selected by the researcher on the site based on his knowledge. This was also combined with "snowballing" as some respondents directed the researchers to potential respondents who constituted part of the population of interest (immigrant vendor of African origin).

\subsection{Population of study, study sites and instrument}

The population of interest in the study was that of immigrant street vendors from other African countries. The population was chosen by the researcher because of his interest in African migrants and also because they constitute the majority of poor immigrants in urban South Africa who depend largely on the informal sector in general and street vending in particular for their livelihoods.

The study was based in some suburbs of Cape Town. The sample was drawn from five main suburbs namely: Bellville, Parow, Wynberg, Mitchells Plain and the CBD (Cape Town Central). Some road junctions were also visited to select some participants. These sites were chosen based on the researcher's knowledge of the trading sites in Cape Town. Caution was however taken to avoid the "concentration bias" as the sites were sufficiently separated from each other.

A semi-structured questionnaire was used to collect the data for this study. The questionnaire was made up of both closed-ended and open-ended questions. Open-ended questions were used in cases where a wide range of answers (mostly qualitative) was anticipated which were later categorized during the data analysis phase. The strategy of openended questions in the questionnaire instrument was used to get detail information about the past experiences (sort of narratives) of the respondents which are needed to test the hypotheses of the research (despite of this procedure not being common in quantitative studies).

\subsection{Data Collection}

The data collection process took place between 28th of June 2010 and the 13th of August 2010 during which a total of two hundred and eight (208) questionnaires were administered in the 5 conveniently selected main sites and other road junctions in Cape Town. The total of 500 questionnaires had been envisaged but this number could not be achieved mainly due to the time factor and logistical problems. The administration of the questionnaires took the form of face-to 
face interviews with the respondent which necessitated some time and patience as it was done in the respondents' place of activity.

\subsubsection{Sampling}

The Sampling method used in the study was purposive where access to the respondent was through direct and indirect contact. Direct access was by the introduction of the subject matter to the potential respondent and the explanation of the raison d'être of the project to have his or her consent (as seen on the cover page of the questionnaire). Indirect access otherwise known as "snowballing" as mentioned earlier was used when potential respondents appeared suspicious and skeptical of what we were out for. After the preliminary introduction by the third party (known respondent), the researcher then explained the whole process to the potential respondent to get his or her full consent. Respondents were selected subjectively on the sites while caution was taken to make sure there was no bias of any nature. There was no gender, nationality, age or other preferences (apart from ensuring that the potential respondent was an immigrant from any other African country. However, we were guided by the idea of representativeness of the sample.

\subsection{Methods of Analysis}

In order to answer the research questions, the following procedure was used in the data analysis. The Statistical Package for Social Science (SPSS version 19) was used to analyse the data and the analysis was basically descriptive as inferential statistics could not be used due to the lack of viable data on the study population as a whole. Hence the external validity of the instrument cannot be ascertained.

The general quality of the data collected can be said to be good as the rate of non-response was relatively low $(0.832 \%)$ judging from the fact that two hundred and eight (208) questionnaires out the initial two hundred and fifty questionnaires printed for the field work were effectively administered.

The information from the questionnaires was first coded and entered into a database developed to this effect. During the process, the open-ended questionnaires were categorized following the responses from the field. The spatial migratory trajectories were traced from the type of transport means used to get into the country to determine whether they were direct or indirect as well as the number of countries the migrant passed through

\section{Results and Discussions}

\subsection{Social Trajectories}

This section examines the social adaptations made by the migrant vendors to ease their migration and insertion into the host society. We will look at the way these vendors get accommodation and further strategies of social improvement like further work and/or education. This section also sheds some light on the use of networks and social capital as a whole.

\subsubsection{The Role of networks in the Migration of the vendors}

One sees a strong influence of social networks in the migration process of these vendors as more than $68 \%$ of them got the advice to migrate from close relations while $66.3 \%$ of the vendors received supplementary (encouraging) information from other persons already residing in the country before their actual migration into the Country. Besides information support, other forms of support included material, financial and moral support as noted in table 1 below:

Table 1: Support received from persons in South Africa

\begin{tabular}{|l|c|c|}
\hline & Frequency & Percent \\
\hline financial & 49 & 23.6 \\
material & 2 & 1.0 \\
both financial and material & 33 & 15.9 \\
moral & 49 & 23.6 \\
none & 33 & 15.9
\end{tabular}




\begin{tabular}{|l|c|c|}
\hline all three & 13 & 6.3 \\
not applicable & 29 & 13.9 \\
Total & 208 & 100.0 \\
\hline
\end{tabular}

From table 1 , it can be noted that only $15.9 \%$ of the vendors had not received any form of support from anybody resident in the country. This may suggest that they got all the support they needed from relations and acquaintances in the countries birth or origin. On the other hand, about 70 percent of the vendors had received some form of help from people who have migrated and resided in the country before their arrival with about 39 percent having received material/financial assistance. This is a clear indication of the strong influence of social networks in the migration and insertion of the migrant vendors.

\subsubsection{Accommodation}

The problem of getting accommodation (especially first accommodation) is always primordial for an immigrant and is not different with immigrant street vendors in urban South Africa. We find the strong influence of social capital in resolving the problem of (first) accommodation for the immigrant vendors as $49 \%$ of them rely on strong family ties with their family members in South Africa for accommodation (at least first place of stay) while a further $21.2 \%$ and $12 \%$ rely on friends/acquaintance and countrymen respectively for their initial accommodation (see table 2 below).

Table 2: Initial accommodation

\begin{tabular}{|l|c|c|}
\hline Source of first accommodation & Frequency & Percent \\
\hline Relation in South Africa & 102 & 49.0 \\
Friend/acquaintance & 44 & 21.2 \\
Fellow countrymen & 25 & 12.0 \\
Myself & 11 & 5.3 \\
Other & 26 & 12.5 \\
Total & 208 & 100.0 \\
\hline
\end{tabular}

Disparities can be seen between the various nationalities in accommodation. It can be seen that the vendors from Burundi and Somali depend most on personal efforts in order to get accommodation. This situation ties with the earlier analysis on assistance before migration and where migrant vendors from these countries depend least on social networks and can be explained by the very reason of war-torn countries that leads to unplanned migration of their citizens while vendors from Congo Brazzaville and DRC depend mostly on the family members for in solving the problem of accommodation ( $66.7 \%$ and $60 \%$ respectively) as seen on table 3 .

Table 3: Nationality and accommodation within the first month in South Africa.

\begin{tabular}{|c|c|c|c|c|c|c|}
\hline \multirow[b]{2}{*}{ Nationality } & \multicolumn{6}{|c|}{ Person responsible for first accommodation in S.A } \\
\hline & relation & Friends & $\begin{array}{l}\text { Fellow } \\
\text { country- } \\
\text { men }\end{array}$ & self & other & Total \\
\hline
\end{tabular}




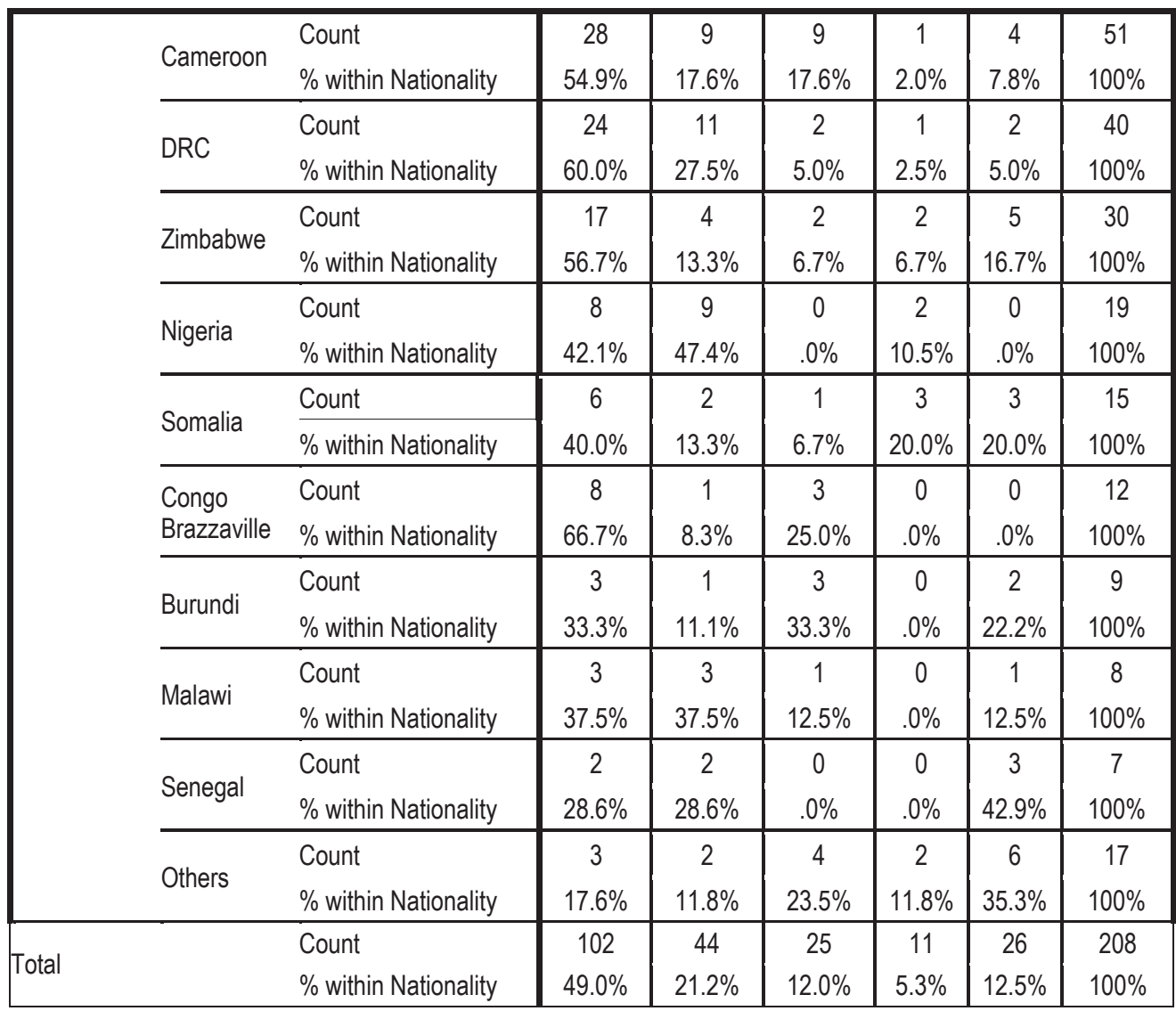

Statistics from the sample also show that $71.6 \%$ of the vendors had changed their initial residences for various reasons seen in table 4 below.

Table 4: Reasons for change of residences

\begin{tabular}{|l|c|c|c|}
\hline \multirow{2}{*}{ Main Reasons } & \multicolumn{3}{|c|}{ Percentage per residential Suburbs } \\
\cline { 2 - 4 } & Initial Suburb & Suburb 2 & Suburb 3 \\
\hline Family-related issues & 18.1 & 1.3 & 0.7 \\
\hline Environmental issues (dirty area, overcrowding, etc) & 12.8 & 8.2 & 1.3 \\
\hline Business(activity)-related e.g. close to business site, etc & 12.1 & 11.4 & 7.4 \\
\hline management issues (e.g. lease expired, property sold, etc) & 16.1 & 7.4 & 1.3 \\
\hline Insecurity (e.g. xenophobia, theft) & 6.7 & 5.4 & 1.0 \\
\hline other reasons & 30.2 & 13.4 & 5.4 \\
\hline not applicable & 3.4 & 53.0 & 81.9 \\
\hline
\end{tabular}


It can be noted from table 4 above that the proportion of vendors who change their residences decreases at each suburb as indicated by the increase in the proportion of 'not applicable' response. This may mean than vendors become more and more stable as time goes on. It also be seen that family-related issues are the dominant reason for change of residence. These include change of marital status, arrival of another family relation and just an increase in the family size staying together that warrant the migrant vendor to look for another residence. Business-related causes of change of residence only start dominating as from the second residence. This is probably when the immigrant vendors start experiencing some stability and start looking for more suitable business ventures and locations. Incidentally, insecurity plays the least role at all suburbs in determining whether the migrant vendor should move or not as seen from the proportions that are lowest at all suburbs. This can be interpreted as a sign of a good relationship between the immigrant vendors and the host communities contrary the what one might think to be the impact of xenophobia that has been widespread in most informal settlements in the country before this time (survey period). It should be noted that the causes of residential mobility might be multiple but here we are dealing only with the main ones.

\subsubsection{Affiliation to associations}

It can be seen from table 6 below that almost half of the vendors are members of at least an association but the majority belong to their ethnic unions/associations rather than street traders unions (see table 5).

Table 5:Affiliation to association and membership in various associations

\begin{tabular}{|l|c|c|}
\hline Affiliation to association(s) & Frequency & Percent \\
\hline & 94 & 45.2 \\
\hline Yes & 114 & 54.8 \\
\hline No & 208 & 100.0 \\
\hline Total & \multicolumn{2}{|}{} \\
\hline Membership in various associations \\
\hline Associations & 70 & 33.7 \\
\hline Ethnic/Countrymen & 43 & 20.7 \\
\hline Hawkers & 1 & 0.5 \\
\hline African immigrants & &
\end{tabular}

From table 5 above, one may draw that the street vendors surveyed seem to benefit more from ethnic associations $(33.7 \%)$ than the other noted associations. These ethnic associations help in maintaining the social networks through which these migrant vendors can get information on almost everything concerning their lives in the host country and even beyond. Hawkers associations play mostly regulatory roles in collaboration with municipalities. However, a cross-country comparism noted differences in the rate of affiliation among the countries surveyed. It will be seen that idea of belonging to a grouping is very high among Cameroonian and Nigerian vendors while very low among vendors from Congo Brazzaville and Malawi. This reflects perhaps the cultural differences between the various nationals (see table 6).

Table 6: Nationality and affiliation to associations

\begin{tabular}{|cl|c|c|c|}
\hline \multirow{2}{*}{ Nationality } & \multicolumn{2}{|c|}{ Affiliation to an association } & \multirow{2}{*}{ Total } \\
\cline { 3 - 4 } & Yes & No & \\
\hline \multirow{2}{*}{ Cameroon } & 41 & 10 & 51 \\
DRC & 13 & 27 & 40 \\
Zimbabwe & 3 & 27 & 30 \\
Nigeria & 12 & 7 & 19 \\
\hline
\end{tabular}




\begin{tabular}{|c|c|c|c|c|}
\hline & Somalia & 7 & 8 & 15 \\
\hline & Congo Brazzaville & 1 & 11 & 12 \\
\hline & Burundi & 6 & 3 & 9 \\
\hline & Malawi & 1 & 7 & 8 \\
\hline & Senegal & 3 & 4 & 7 \\
\hline & Others & 7 & 10 & 17 \\
\hline Total & & 94 & 114 & 208 \\
\hline
\end{tabular}

A further investigation into the results in table 6 which revealed that the street vendors are more likely to join an ethnic association than otherwise, cross country comparism also noted discrepancies in the preferences of the countries studied as noted in table 7.

Table 7: Nationality and affiliation to ethnic association

\begin{tabular}{|c|c|c|c|c|c|}
\hline & & & $\begin{array}{r}\text { Associa } \\
\text { co } \\
\end{array}$ & $\begin{array}{l}\text { f ethnic or } \\
\text { men }\end{array}$ & Total \\
\hline & Nation & & Yes & No & \\
\hline & Cameroon & Count & 39 & 12 & 51 \\
\hline & & $\%$ within Nationality & $76.5 \%$ & $23.5 \%$ & $100.0 \%$ \\
\hline & DRC & Count & 7 & 33 & 40 \\
\hline & & $\%$ within Nationality & $17.5 \%$ & $82.5 \%$ & $100.0 \%$ \\
\hline & Zimbabwe & Count & 0 & 30 & 30 \\
\hline & & $\%$ within Nationality & $.0 \%$ & $100.0 \%$ & $100.0 \%$ \\
\hline & Nigeria & Count & 12 & 7 & 19 \\
\hline & & $\%$ within Nationality & $63.2 \%$ & $36.8 \%$ & $100.0 \%$ \\
\hline & Somalia & Count & 4 & 11 & 15 \\
\hline & & $\%$ within Nationality & $26.7 \%$ & $73.3 \%$ & $100.0 \%$ \\
\hline & Congo Brazzaville & Count & 1 & 11 & 12 \\
\hline & & $\%$ within Nationality & $8.3 \%$ & $91.7 \%$ & $100.0 \%$ \\
\hline & Burundi & Count & 0 & 9 & 9 \\
\hline & & $\%$ within Nationality & $.0 \%$ & $100.0 \%$ & $100.0 \%$ \\
\hline & Malawi & Count & 0 & 8 & 8 \\
\hline & & $\%$ within Nationality & $.0 \%$ & $100.0 \%$ & $100.0 \%$ \\
\hline & Senegal & Count & 3 & 4 & 7 \\
\hline & & $\%$ within Nationality & $42.9 \%$ & $57.1 \%$ & $100.0 \%$ \\
\hline & Others & Count & 4 & 13 & 17 \\
\hline & & $\%$ within Nationality & $23.5 \%$ & $76.5 \%$ & $100.0 \%$ \\
\hline & & Count & 70 & 138 & 208 \\
\hline & & $\%$ within Nationality & $33.7 \%$ & $66.3 \%$ & $100.0 \%$ \\
\hline
\end{tabular}


Up to $76.5 \%$ and $63.2 \%$ of vendors from Cameroon and Nigeria respectively belong to an ethnic association. Other countries that had remarkable representation in ethnic associations include Senegal, Somalia, and DRC.

\subsection{Economic Trajectories}

The social capital theory (specifically the Migration network theory) has been used to explain the persistence of migration (Light 1989; 2004). The theory can also be used to explain the choice of market niche used by immigrants for integration in their host countries. Through their social networks, these immigrants can easily answer the question of "what to do? where and how to do it"? The question of what to do was answered for many of the street vendors (26\%) by friends, family members or mere acquaintances that had been in the country before the would-be vendor. This is illustrated by table 8 below.

Table 8: Reason for doing business (hawking)

\begin{tabular}{|l|c|c|}
\hline Possible Reasons & Frequency & Percent \\
\hline First acquaintance in S.A introduced me to it & 54 & 26.0 \\
No official document to get employed in S A & 22 & 10.6 \\
No Qualification & 29 & 13.9 \\
Wanted to be boss of myself & 58 & 27.9 \\
No other choice & 31 & 14.9 \\
Other reason & 14 & 6.7 \\
Total & 208 & 100.0 \\
\hline
\end{tabular}

It should be noted that only a relatively small proportion decided to do hawking due to lack of official documents (identification documents, work permits, etc.) or lack of qualification that could permit them to get formal employment. This confirms earlier findings on the educational level of the vendors which is not very low while also showing that most of the vendors also had official documents that could permit them to search for formal employment but chose street vending for other reasons. It should also be noted that these are only main reasons for engaging in street vending and in most cases many reasons may be responsible ( which may include all of the above-anticipated) for the choice of doing informal trading by migrants.

Taking a deeper look of the network aspect in business (street vending), one would also notice the strong influence of the connections made by the immigrant vendors when one looks at the source of initial capital and how the vendors actually got involved in this trade.

\subsubsection{Source of capital}

Despite the small capital needed to start-up the activity, immigrants still have to ponder over it. Here, one sees a significant role played by the vendors' social networks as almost half (43.8\%) of the vendors got their start-up capital from relations or friends resident in South Africa. By 'capital' it refers to both fixed and liquid capital needed to start up the business. This of course may also be accompanied by moral support in the form of guidance and advice on how to go about the business. This is further buttressed by the fact that up to $38.0 \%$ of the vendors actually start the carrier by selling with someone they know before later selling for themselves with a further $23.6 \%$ actually starting their experience by selling for others (probably ethnic businesses). This is probably how experience and training is acquired (as pointed out in Pécoud 2005 and Light 2004). One also notes the gender disparity in this aspect as more women than men (64.5\% as against $31.8 \%$ for men) depend on others to start their business.

In terms of how the street vendors were initiated, it was noted that over half (51.5\%) got into the activity by either selling with a relative or working in the domain as an employee during which they probably cultivated the entrepreneurial spirit. This confirms most of the studies in relation to this aspect (Motala 2002; Tanga, 1994). 


\subsubsection{Acquisition of space}

The acquisition of space needed for the activity has always been a problem for vendors in most cases especially in the entrepreneurial city where the activity is highly regulated due to the high economic value attached to urban space. If the acquisition of space is an uphill task for citizens, then is should be tougher for immigrants to get the much needed space for their activity. However, this would be facilitated in the face of strong social networks. The case of immigrant street vendors in urban South Africa is no different. Close to one fifth (19.9\%) of the vendors got their trading spaces directly from relatives or friends who might have either moved to other places or changed their economic activities (see table 9).

Table 9: Acquisition of trading space

\begin{tabular}{|ll|c|c|c|}
\hline & Frequency & Percent & $\begin{array}{c}\text { Valid } \\
\text { Percent }\end{array}$ \\
\hline Just occupy it & 53 & 25.5 & 25.7 \\
& Applied through council or regulatory body & 88 & 42.3 & 42.7 \\
& friend/ relation gave it to me & 41 & 19.7 & 19.9 \\
& Bought it from someone and later register it with the council & 3 & 1.4 & 1.5 \\
& Just occupy it but later registered with the council & 6 & 2.9 & 2.9 \\
& do not know( in case of working for somebody) & 15 & 7.2 & 7.3 \\
& Total & 206 & 99.0 & 100.0 \\
Missing & System & 2 & 1.0 & \\
Total & & 208 & 100.0 & \\
\hline
\end{tabular}

\subsubsection{Market niches of vendors}

It can be seen from statistics that a greater majority of the vendors are involved in the sale of goods as oppose to services. About $27.9 \%$ of the vendors are strictly involved with the provision of services such as haircutting and hairdressing (haircutting is used in the text to refer to the services of barbers while hairdressing refers to the services of hairstylist mostly provided by females) while the sale of general manufactured goods and foodstuff carry the bulk of the market niches in which the vendors are involved. General manufactures carries the highest share of the niches with $32.7 \%$ of the vendors involved in this domain while hairdressing comes second with $22.1 \%$. General manufactures here include items like belts, wallets, sunshades and many others. Foodstuff here covers both cooked and raw food items including vegetables and fruits. The table below gives some details on some of the common commodities and services marketed by these vendors.

Table 10: Market niches of the vendors

\begin{tabular}{|c|c|c|}
\hline Market specialities & Frequency & Percent \\
\hline Footwear & 3 & 1.4 \\
\hline Clothing & 12 & 5.8 \\
\hline Hairdressing & 46 & 22.1 \\
Haircutting & 12 & 5.8 \\
Foodstuff & 3 & 1.4 \\
Cigarettes, sweets and...... & 9 & 4.3 \\
General manufactures & 68 & 32.7 \\
\hline
\end{tabular}




\begin{tabular}{|l|c|c|}
\hline Arts /crafts works & 12 & 5.8 \\
Audio/video CDs & 16 & 7.7 \\
Others & 27 & 13.0 \\
Total & 208 & 100.0 \\
\hline
\end{tabular}

\subsubsection{Market niche and country of birth}

There two different scenarios when it comes to the relationship between country of birth and types of goods/services offered by the vendors namely. This has to do with the duration of residence where one sees a change from one activity of specialty at the beginning to something different at a later stage of stay. The figures below help to show this dichotomy in some cases. The hairdressing domain is dominated at all times by vendors from the two Congos (DRC and Congo Brazzaville) who make up $68.75 \%$ of those selling these services (see fig. 1a and $1 \mathrm{~b}$ ). Cameroonians specialize in the sale of general manufactured goods at all stages of their residence with $50 \%$ when they just arrive and $48.5 \%$ of those selling these goods at a later stage. In fact an average of about $67 \%$ of all Cameroonian vendors are involved in the sale of general manufactured products at all times of their stay. This probably because it is a general phenomenon even back in the country (as noted in Sunkekang, 1998 quoted in Peberdy \& Rogerson, 2000).

Fig 1a: Country of birth and market niche at start

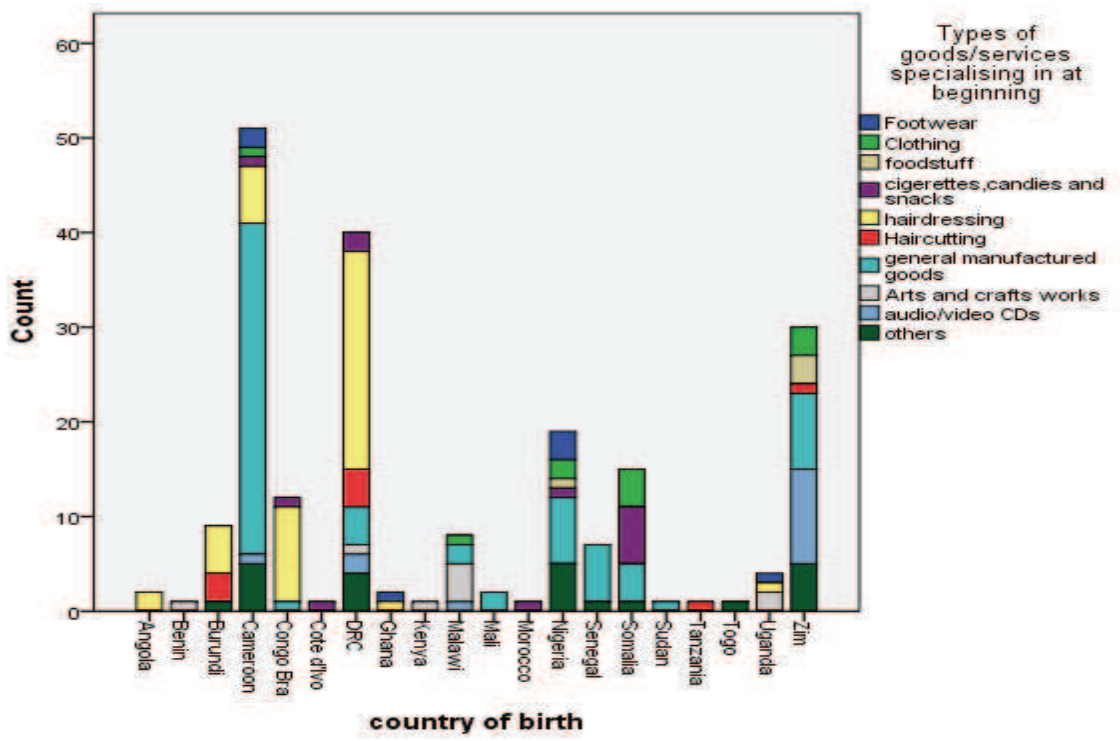

The arts and crafts domain is dominated by vendors from Malawi and Uganda. This is probably because they have experience in the manufacture of sculpture, bronze works and other works of art from their countries of birth. There also exist a kind of network in the importation and distribution of these commodities within most vendors from Southern Africa like DRC, Zimbabwe and especially Malawi. There seem to be an inter-play between the network aspect and the country of birth in determining the type of commodity to be sold by the vendors. Vendors from a particular country specialize in particular commodities at the beginning probably because their fellow countrymen are also engaged in the domain and advise them to also do the same. This is true seen when we look the reason for engaging in the in vending discussed earlier as well as the source of capital. Somalis make up the bulk (more than $46 \%$ ) of those who start their business trajectory by selling cigarettes, snacks and other related items. This is a common phenomenon in Cape Town as a bulk of those brandishing these items in taxi terminals, pavements and train stations are those from Somalia. However they later change to haircutting and the sale of clothing at a later stage. 
Fig. 1b: Country of birth and market niche at a later stage.

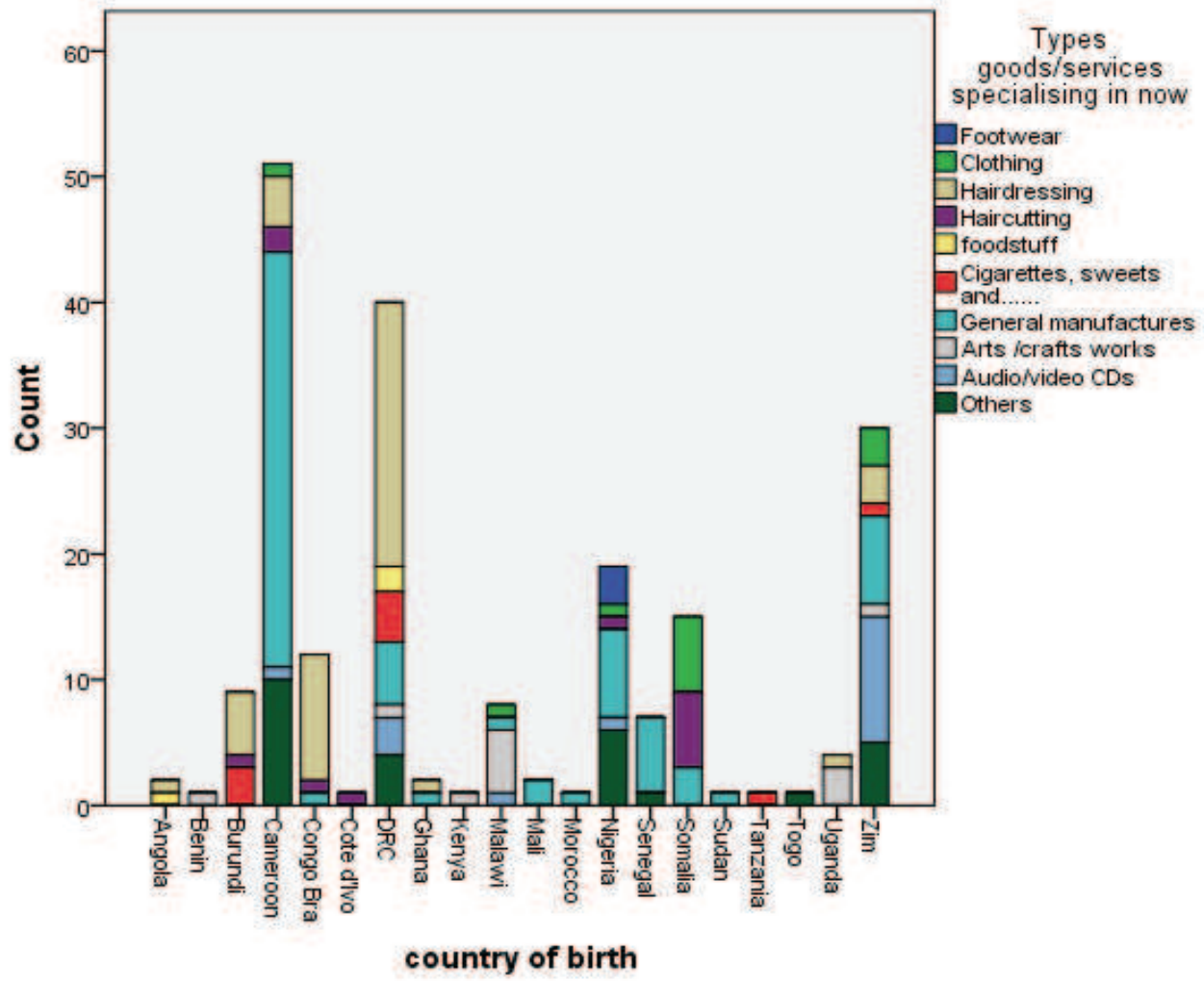

The relationship between nationality and market niche is shown in table 11 below. The Fisher Exact test shows a significant relationship between nationality and market niche as indicated by the p-value of 0.000 which is below 0.05 .It should be noted that the Chi Square could not be used as it was invalid for the test (more $25 \%$ of entries had values less than 5). The value of Crammer $\mathrm{V}$ and Phi also confirm the association.

Table 11: Fisher Exact Tests for nationality and market niche.

\begin{tabular}{|c|c|c|c|c|c|}
\hline & Value & $d f$ & $\begin{array}{l}\text { Asymp. Sig. (2- } \\
\text { sided) }\end{array}$ & $\begin{array}{l}\text { Exact Sig. (2- } \\
\text { sided) }\end{array}$ & $\begin{array}{l}\text { Exact Sig. (1- } \\
\text { sided) }\end{array}$ \\
\hline $\begin{array}{l}\text { Pearson Chi-Square } \\
\text { Likelihood Ratio } \\
\text { Fisher's Exact Test } \\
\text { Linear-by-Linear Association } \\
\mathrm{N} \text { of Valid Cases }\end{array}$ & $\begin{array}{c}347.143^{\mathrm{a}} \\
265.402 \\
.000 \\
1.955 \\
208\end{array}$ & $\begin{array}{l}81 \\
81\end{array}$ & $\begin{array}{l}.000 \\
.000\end{array}$ & $\begin{array}{c}. b \\
. b \\
.000 \\
b\end{array}$ & b \\
\hline
\end{tabular}

a. 90 cells $(90.0 \%)$ have expected count less than 5 . The minimum expected count is .10 .

b. Cannot be computed because there is insufficient memory.

\subsubsection{Market niche and past experience}

It is postulated that many immigrant entrepreneurs are mostly endowed with survival strategies from home countries or with experience gotten throughout their migratory trajectory. It therefore appears that there is little formal training in this domain especially in street trade. However, certain services sold on the streets of urban South Africa such as 
hairdressing and barbing may require some formal training but this seem not to be the case with immigrant street vendors. Vendors rely much on their relations for "on the job" training. .

The study revealed that $55.3 \%$ of the vendors had previous experience in their line of activity while $44.7 \%$ of them did not. Expanding this line of enquiry, it came to the fore that only $16.3 \%$ of the vendors had actually been trained in the particular activity. This is a clear indication that the marketing skills are acquired through the practice. This also confirms the assertion that street vending requires little skill and experience and the reason why it is a very suitable activity of insertion for immigrants in their host country.

No significant relationship between past experience in an activity and the market niche of the migrant vendors as noted by a p-value above $0.05(0.577)$ for the Fisher Exact test. The afore mentioned test shows that experience in migration do not contribute significantly in the insertion of migrants in the entrepreneurial city while nationality and of cause the social networks associated with nationality play a major role in the choice of market niche of the immigrants in the cities of South Africa.

\subsubsection{Profits}

The monthly profit margin of the street vendors surveyed was done by analysing the profits just after startup and at the time of the survey (see table12). There was a wide gap between the profit margin at the beginning of the business and at the time of the survey. For example the average monthly profit at the beginning was 1900 Rands while at the time of the survey, it is about 3100 Rands. This reflects perhaps a normal situation in a business where at the beginning one may not have as much profits as compared to when the business is already stable. It should be noted that the total number of vendors dropped when it comes to the aspect of profit due to the fact that some of the vendors were reluctant to declare their monthly profits for personal reasons.

Table 12: Statistics on monthly profits:

\begin{tabular}{|l|c|c|}
\hline & Situation at Start of business & Situation at present \\
\hline Total & 176 & 184 \\
\hline Mean (in Rands) & 1942.7841 & 3131.5217 \\
\hline Mode (in Rands) & 1000.00 & 2000.00 and 4000.00 \\
\hline Median(in Rands) & 1600.00 & 3000.00 \\
\hline Minimum(in Rands) & 80.00 & 400.00 \\
\hline Maximum(in Rands) & 10000.00 & 8500.00 \\
\hline Range (in Rands) & 9920.00 & 8100.00 \\
\hline Variance (in Rands) & 1411.62062 & 1721.66709 \\
\hline
\end{tabular}

It can be said that that the profit margins are encouraging as none of the vendors is absolutely poor (living on less than one dollar or approximately 7 Rands a day). Only $13 \%$ of the vendors lived on less than a thousand rands while up to $20 \%$ of the vendors had five thousands and more as profits per month at the time of the survey. The results noted here are consistent with Tengeh et al's study (2012) which concluded African immigrant -owned businesses experience a financial growth.

\section{Conclusion}

This study investigated the means used by immigrants for their insertion into the economic landscape of the entrepreneurial cities of their host countries using street vendors in Cape Town as a case study. The concept of social network was central in the explanation of the mechanism of immigrant insertion in the entrepreneurial city. It helped to explain some of the strategies used by immigrants for their insertion into the market space of urban areas in the destination country. The following conclusions could be drawn from this study:

Firstly, the experiences gained directly or indirectly through (advise) during the migratory process and subsequently during insertion tend to play a significant role in determining whether an immigrant is initiated in street vending or not, what he/she trades in, where to trade and so forth. Secondly, given that migration necessitates the establishment of various relationships, one notices the overwhelming role played by a street vendor's social networks as 
far as the acquisition of trading space is concerned. Thirdly, given that more than two third of street vendors were provided accommodation on arrival by someone residing in the country whom they knew before their arrival, one sees the invisible hand of the immigrants social networking (social capital) in facilitating migration and insertion in the host country. Changing residential address was consistent with the process of insertion and integration (until some stability is achieved). Further change of residence is mainly as a result of other factors such as location of activity and property managerial issues like the sale of residential property or expiration of the lease. In sum the economic activity influences the change of residence only after the immigrant has had some stability in the activity. Finally, by engaging in street vending, a significant proportion of the immigrants surveyed were able improve on their human capital as the case may be through further education as well as to lift themselves above the poverty line. The foregoing results point to the fact that that nationality underpinned by social networks was a major factor in the socio-economic trajectories of immigrants in urban South Africa.

\section{References}

Crossa, V. (2009). Resisting the Entrepreneurial City: street vendors struggle in Mexico City's Historic Centre in International journal of Urban and Regional Research, vol.331, Blackwell.

De Haas, H. (2009). Trans-Saharan and Trans-Mediterranean migration: questioning the transit hypothesis. Paper presented at ESF SCSS Exploratory Workshop: The Human Costs of Border Control in the Context of EU Maritime Migration Systems, Vrije Universiteit Amsterdam, Netherlands, 25-27 October.

Gidengil E. \& Stolle D. (2009). The role of social networks in immigrant women's political incorporation in International Migration Review, vol. 43:4, pp 727-763.

ILO (2002). Men and Women in the Informal Economy: A Statistical Picture. International LabourOrganisation publication.

Jenny A. (2009). Street trade, beach trade on struggles over public space in Zanzibar. (unpublished thesis).

Kamala S. et al. (n.d). Street Vendors in India in WIEGO Law Project on the Informal Economy: unpublishedmanuscript.

Keith P, F. (1998). Introduction to Social Research: Quantitative and qualitative approaches. SAGE publications.

Light I., Bhachu, P. \& Karageorgis, S. (1989): "Migration Networks and Immigrant Entrepreneurship" in California Immigrants in world perspective: The Conference papers, vol.5- 1989-90.

Light I. (2004). "Immigration and ethnic economies in giant cities" in 2004 UNESCO Publication,Blackwell publishing Ltd.

Lund, F. (1998). Women street vendors in urban South Africa: A synthesis of selected research findingsCSDS research report no. 15. University of Natal.

Peberdy, S and Rogerson, C. (2000). "Transnationalism and Non-South African Entrepreneurs in South

Africa's small, medium and Micro-Enterprise (SMME) economy" in Canadian Journal of African studies, Vol. 34(1), Canadian Association for African studies.

Motala S. (2002). Organizing in the informal economy: A case study of street trading in South Africa. SEED working paper No. 36. International Labour Organisation.

Myron W. \& Teitelbaum M.S. (2001). Political Demography, Demographic Engineering, Berghahn Books.

Nontyatyambo P (2009). Fighting poverty and saving street vendors in South Africa. The Globalist. www.theglobalist.com/global development. Accessed on 05 May 2010.

Peberdy, S and Rogerson, C. (2000). "Transnationalism and Non-South African Entrepreneurs in South Africa's small, medium and Micro-Enterprise (SMME) economy" in Canadian Journal of African studies, Vol. 34(1), Canadian Association for African studies

Schapendonk, J. (2012). Turbulent Trajectories: African migrats on their way to the EuropeanUnion. Societies, (2):27-41.

Tanga P. (1994). Informal Sector and Poverty: The case of Street Vendors in Lesotho. Ossrea publications.

Tara P. (2008). Migrant employment in South Africa: New data from the Migrant Rights Monitoring Project In: Galo-Mosala S. (Ed). Migrant experiences within the South African labour market, pp 35-50. Scalabrini Centre of Cape Town.

Tim E. (2008). Networks and their Influence on Migration Policies: Conclusions from the Romanian-Spanish Migration Space. Policy Brief no.11, Hamburg Institute of International Economics http://www.focusmigration.org. Accessed on 4th May 2010.

Tengeh, R.K., Ballard, H. \& Slabbert, A. (2011). A Framework for Acquiring the Resources Vital for theStart-up of a Business in South Africa: an African Immigrant's Perspective, European Journal of Social Sciences, 23 (3): 362-381.

Tengeh, R.K., Ballard, H. \& Slabbert, A. (2012). Do immigrant-owned businesses grow financially? An empirical study of African immigrant-owned businesses in Cape Town Metropolitan Area of South Africa. African Journal of Business Management , 6(19): 6070-6081.

Vicki R. (2005): "City Squeezes Soul from Trade" in Mail and Guardian of July 22-28.

Zuberi T. \& Sibanda, A. (2005). Migration and employment in Zuberi, Sibanda \& Udjo (Eds). The Demography of South Africa. M.E Sharpe, New York. 
